\title{
Evaluation of Slag as aggregates in Asphalt Mixtures
}

\author{
Leif Viman ${ }^{1,}$ a , Abubeker W. Ahmed ${ }^{1}$, Safwat Said ${ }^{1}$, Lotta Lind ${ }^{2}$ \\ 1 VTI, Linköping, Sweden \\ 2 Lindskan AB, Ange, Sweden \\ a leif.viman@vti.se \\ Digital Object Identifier (DOI): dx.doi.org/10.14311/EE.2016.238
}

\begin{abstract}
During the last decade, the Swedish Transport Administration together with contractors, Steel industry in Sweden and the Swedish National Road and Transport Research Institute have built test road sections with Steel slag in various locations in Sweden. Steel slag has well-known good adhesion, durability, wear resistance and noise reducing properties. This project pointed out the importance for steel slag producers to produce a slag quality that fulfils the requirements as road material, where also particle emission is an important issue. There are over 10 producers of steel slag in Sweden.

There are several goals for using steel slag in asphalt mixes; mainly longer technical lifetime caused by good wear resistance against studded tyres, good stability performance in binder and base course, and good durability performance, the latter being especially important in porous asphalt, where it also potentiallygives some noise-reducing effects. In addition, the environmental aspects in terms of particle emission, were an important issue for this project. So far, test sections show good performance according to road surface measurements. Laboratory test according to European standards for aggregate and several road simulator test for wear resistance and particle emission have been performed during the last five years by means of the unique road simulator at VTI. An important part of the project is to increase the knowledge for the steel slag producers to develop a material that fulfils the requirements for road material in as many aspects as possible, both technical and environmental issues. The results are so far promising and expectations are met.
\end{abstract}

Keywords: Slag, Testing 


\section{INTRODUCTION}

The steel industries in Sweden produce slag by-products regardless of the raw materials or the processing technology, or which grades of steel produced. More than $80 \%$ of the slag by-product is used for various applications which have significant environmental benefits. One of those applications where slag is often used is in the construction industry; e.g. for road structures where slag materials exhibit good characteristics as both bound and unbound materials [1]. It is also well known that, in addition to the environmental benefits, the use of slag aggregates produces asphalt mixtures exhibiting superior performance compared to those manufactured with natural aggregate. Slag asphalt thus has the potential to results in roads with longer lifetime and lower maintenance costs, properties which were further explored during this project. Iron and steel slags are well known for having many qualities, which makes them very useful as aggregate in asphalt. Slag alkaline properties together with the acidic properties of the bitumen provide good adhesion between aggregate and binder, which has a positive effect on the stability. The rough surface of the slag aggregate also enhances the shear resistance of the mixture. Moreover, thanks to the porosity of slag aggregate [1,2], Noise dampening properties are obtained from slag asphalt surface mixtures. These desirable characteristics would make the slag aggregates a natural choice for roads in urban areas such as at roundabouts, traffic lights and bus stops where high shear strength is important and where traffic noise is also of main concerns.

Field performance of few test sections consisting of slag asphalt surfacing which have been followed for over 6 years indicated very promising results in terms of stability, stiffness, durability and noise reduction [2].

In spite of the stated merits slag aggregates and slag asphalt mixtures possess, a very limited application of slag asphalt is practiced in the Swedish road construction industry.

This study considered ten different slag aggregate materials from different Swedish slag suppliers/steel producers i.e., the slags were obtained from different production processes and variations in physical and mechanical properties of the different slags were therefore expected. In addition, nine of the ten slag aggregate materials considered in this study are REACH (the EU Regulation on Registration, Evaluation, Authorization and Restriction of Chemicals) registered products to ensure the safety of health and environment. All the tests carried out for the registration has demonstrated that none of the standard steel slag types investigated are hazardous to human health or the environment [3].

\section{OBJECTIVES}

The main objective of this study was to evaluate the performance of slag asphalt mixtures using various laboratory tests conducted on the slag aggregates and slag asphalt mixtures. The study focused on slag aggregates that are already used as aggregate in asphalt pavements, where the desired characteristics are good adhesion and noise reduction properties, as well as good stability and durability.

Table 1 summarizes the laboratory tests conducted on the slag aggregate and the slag asphalt mixes. The tests were conducted according to European standards (CEN methods).

Table 1: Test methods conducted on the slag aggregates and slag mixes

\begin{tabular}{ccc}
\hline Aggregate tests & Slag mix tests & Remark \\
\hline Nordic Ball Mill (EN 1097-9) & Prall (EN 12697-16, Method A) & Resistance to wear due to studded tires \\
\hline $\begin{array}{c}\text { Los Angeles abrasion } \\
\text { (EN 1097-2) }\end{array}$ & $\begin{array}{c}\text { Dynamic Creep } \\
\text { (EN 12697-25, Method A) }\end{array}$ \\
\hline Micro-Deval (EN 1097-1) & Dynamic Shear Modulus & Similar to the Superpave shear tester [4] \\
\hline Flakiness index (EN 933-3) & & Test for particle shape \\
\hline
\end{tabular}

\section{MATERIAL DESCRIPTION}

\subsection{Laboratory produced test specimens}

The slag aggregates were collected from ten different Swedish slag suppliers/steel producers. Depending on the purpose and steel production process, there are differences in all properties of the slags produced. Therefore, the physical and mechanical properties of the slag aggregates such as density and water absorption index were first investigated through standard test procedures.

A stone mastic asphalt mix (SMA) according to EN 13108-5 (ABS 11 70/100 and ABS 8 70/100) and a conventional dense graded asphalt concrete binder mix according to EN 13108-1 (ABb 16 70/100) were selected to evaluate the slag asphalt mix performances. The mixes were made of a 70/100 penetration graded bitumen and maximum aggregate size of 8,11 or $16 \mathrm{~mm}$. The grain size distribution for the mixes were selected according to the recommendation by Swedish Transport Administration. The fine fractions of the mixes (0-4 mm) consisted of granite and the rest (> $4 \mathrm{~mm})$ consisted of the respective slag materials. No adhesion material was added.

The ABS 11 70/100 mixes were used for Prall test and the ABb 16 70/100 mixes were used for dynamic creep and dynamic shear modulus tests. For the Prall test, the ABS 11 mix specimens were compacted by the Marshall method. For the other tests, the asphalt specimens were drilled from roller compacted asphalt slabs prepared in the laboratory according to EN 12697-33. 
A conventional mix made of granite with similar grain size distribution and binder grade was also prepared as a reference mix.

Furthermore, depending on the water absorption capacity of the slag aggregate (EN 1097-6) and the density, the applied binder content was adjusted in order to compensate for the binder absorbed in the pores of the slag aggregate and for the varying density [5]. Table 2 presents the physical and mechanical properties the slag aggregates, the binder content of the corresponding mixes and the binder content adjustment.

Table 2: Mixture properties of laboratory prepared specimens

\begin{tabular}{cccccccc}
\hline \multirow{2}{*}{$\begin{array}{c}\text { Slag Id } \\
\text { No. }\end{array}$} & $\begin{array}{c}\text { Water } \\
\text { absorption } \\
{[\%]}\end{array}$ & \multicolumn{2}{c}{$\begin{array}{c}\text { Particle density } \\
\text { g/cm }\end{array}$} & $\begin{array}{c}\text { Target } \\
\text { Binder } \\
\text { content [\%] }\end{array}$ & \multicolumn{2}{c}{$\begin{array}{c}\text { Binder content } \\
\text { adjustment }\end{array}$} & $\begin{array}{c}\text { Applied } \\
\text { Binder } \\
\text { content }\end{array}$ \\
\cline { 2 - 8 } & Slag & Mix $^{a}$ & & Density & Porosity ${ }^{b}$ & {$[\%]$} \\
\hline 1 & 1.5 & 3.57 & 3.13 & 5.0 & -0.8 & 0 & 4.2 \\
\hline 2 & 4.2 & 2.54 & 2.58 & 5.0 & 0.1 & 1 & 6.1 \\
\hline 3 & 3.7 & 2.83 & 2.75 & 5.0 & -0.2 & 1 & 5.8 \\
\hline 4 & 4.3 & 2.67 & 2.66 & 5.0 & 0.0 & 1 & 6,0 \\
\hline 5 & 3.1 & 2.67 & 2.66 & 5.0 & 0.0 & 0.5 & 5.5 \\
\hline 6 & 2.3 & 3.67 & 3.16 & 5.0 & -0.8 & 0.5 & 4.7 \\
\hline 7 & 1.7 & 3.22 & 2.96 & 5.0 & -0.5 & 0 & 4.5 \\
\hline 8 & 2.2 & 3.51 & 2.66 & 5.0 & 0.0 & 0.5 & 5.5 \\
\hline 9 & 4.4 & 3.43 & 3.06 & 5.0 & -0.7 & 1 & 5.3 \\
\hline 10 & 3.0 & 3.58 & 3.13 & 5.0 & -0.8 & 0.5 & 4.7 \\
\hline 11 & 1.1 & 2.64 & 2.66 & 5.0 & 0.0 & 0 & 5.0 \\
\hline
\end{tabular}

${ }^{a}$ The density of the proportioned mixture of slag and conventional aggregate.

${ }^{b}$ Porosity is adjusted with respect to water absorption.

Figure 1 shows the air void of the various $\mathrm{ABb} 16$ 70/100 slag asphalt mixes and reference mix. Note, in this stage, the target was not an optimum mix design of each mix because it would be very extensive study, neither an entire comparison between slag sources at same air voids content. It is rather an evaluation of the already used slags in road pavement as reported above. Differences in air voids content might results in differences in performance evaluations of the slags.

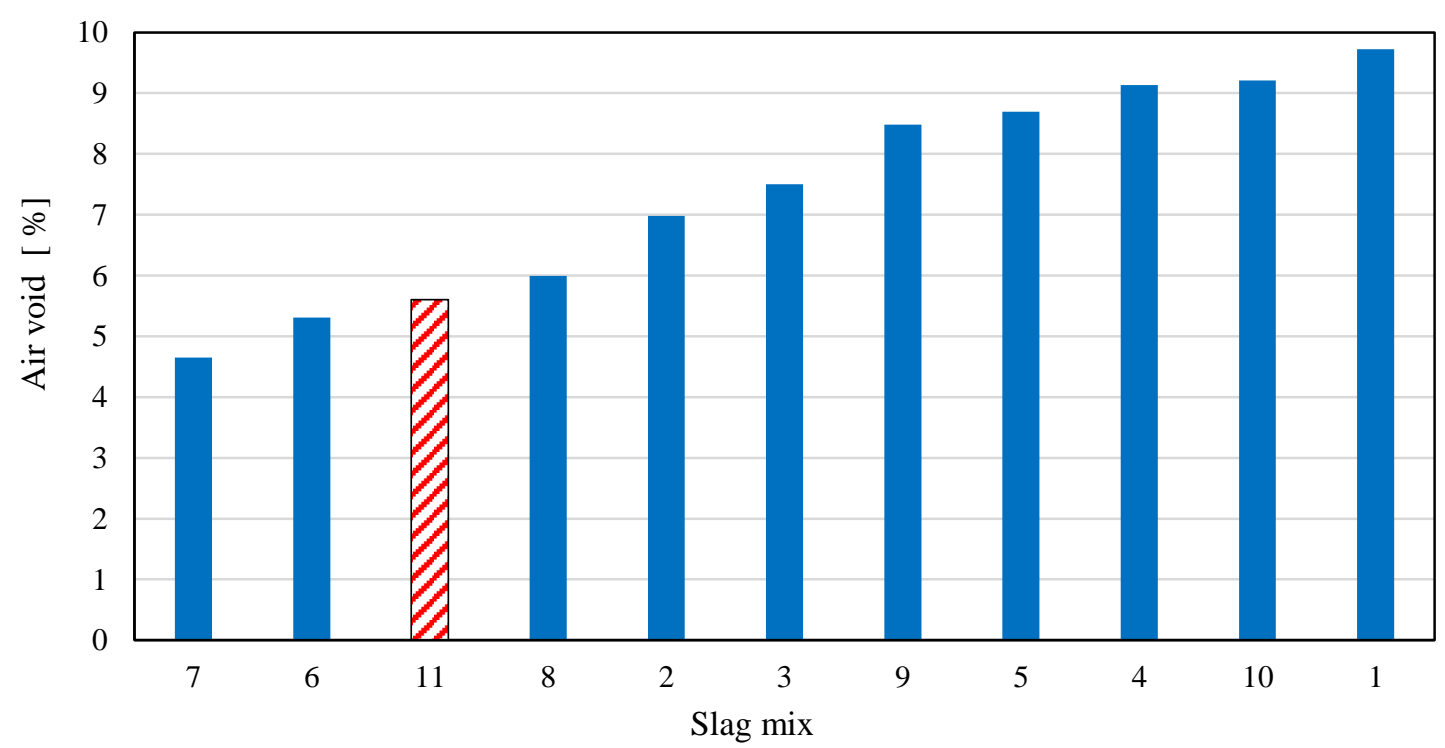

Figure 1: Air void content in the slag asphalt mixes (No 11 is the reference mix) 


\section{TEST METHODS}

The subsequent sections present a brief description of the different test methods that were conducted on the slag aggregates and the slag asphalt mixtures.

\subsection{Slag aggregate performance tests}

Standard test procedures for determining the physical properties of slag aggregates were employed. Tests conducted for determining the toughness and hardness characteristics of aggregate materials were the Los Angeles abrasion (EN 10972) and Micro-Deval (EN 1097-1) tests. Similarly, the Nordic Ball mill test method was employed to determine the resistance to abrasion due to studded tire (EN 1097-9). The Flakiness index of the slag was also conducted according to (EN 933-3) in order to characterize the particle shape distribution.

\subsection{Slag asphalt mixture performance tests}

\section{Prall Test}

The Prall test was employed to evaluate the resistance of asphalt mixtures to abrasion due to studded tires [6,7]. The test was conducted according to the European Standard method A (EN 12697-16) in which a cylindrical asphalt specimen having a diameter of $100 \mathrm{~mm}$ and a thickness of $30 \mathrm{~mm}$ is subjected to abrasive action at a temperature of $5^{\circ} \mathrm{C}$. The specimen is worn by steel spheres (charges) in the presence of water over a standard time period of 15 min. The loss volume is reported as the abrasion value.

\section{Dynamic Creep Test}

Dynamic creep test was conducted to evaluate the permanent deformation characteristics of the slag asphalt binder mixes (ABb 16 70/100). In dynamic creep test, a cylindrical asphalt specimen having a diameter of $150 \mathrm{~mm}$ and a thickness of $60 \mathrm{~mm}$ is subjected to a repeated loading consist of $1 \mathrm{sec}$ load duration and $1 \mathrm{sec}$ rest period. The dynamic creep test is conducted at a temperature of $40^{\circ} \mathrm{C}$. Six specimens per mix type are tested according to the EN 12697-25 Method A.

\section{Dynamic Shear Modulus Test}

The shear resistance of the slag asphalt binder mixes (ABb 16 70/100) were evaluated based on the dynamic shear modulus $\left(G^{*}\right)$ test. The $G^{*}$ test was conducted according to the method and the equipment developed at VTI-Swedish National Road and Transport Research Institute. In this method, the specimen is glued between two steel plates using epoxy. One of the plates can be exposed to sinusoidal or repetitive loading over a range of frequencies. The test is performed on cylindrical samples having a diameter of $150 \mathrm{~mm}$ and a thickness of less than $1 / 4$ of the specimen diameter. Further information on the shear test can be found in [8]. The $G^{*}$ test was conducted at four temperatures: $-5,10,30$ and $50{ }^{\circ} \mathrm{C}$, and 8 loading frequencies: $16,8,4,2,1,0.5,0.1$, and $0.05 \mathrm{~Hz}$. One specimen per mix type are tested.

\section{RESULTS AND DISCUSSIONS}

\subsection{Slag aggregate performance}

The purpose of the slag aggregate tests was to assess their use as aggregates for surface and binder layers mixes in asphalt pavements and to study their advantages over natural aggregates with regard to their porosity and wear resistance. Adhesion is an important parameter for all types of mixes while for wearing course mixes the aggregate wear resistance is decisive. For binder and base course mixes on the other hand the strength and particle shape properties are of higher importance. Thus the wear resistance of the aggregate due to studded tires is determined by the Nordic Ball Mill test. The strength is measured by the Los Angeles and/or Micro Deval while the particle shape characteristics is measured by Flakiness tests.

Table 3 summarizes the results of Los Angeles Abrasion (LA), Micro Deval ( $\left.\mathrm{M}_{\mathrm{DE}}\right)$, Nordic Ball Mill ( $\left.\mathrm{A}_{\mathrm{N}}\right)$ and Flakiness index tests (FI). The tests were conducted on various fractions of the slag aggregates. Road administrations provide standard specifications for these tests depending on the traffic volume and mix types. For instance, according to the Swedish Transport Administration, a $A_{N}$ Value of less than 10, an LA value of less than 25 and an FI value of less than 15 are required for medium to highly trafficked asphalt wearing courses. Requirements for binder and base courses are $\mathrm{M}_{\mathrm{DE}}<20$, LA < 25 and FI < 25 [7]. Consequently, the results in Table 3 demonstrate that the toughness and abrasion properties of most of the slag aggregates match or exceed the requirements for road aggregate materials. 
Table 3: Los Angeles, Micro Deval and Nordic Ball Mill values of the slag aggregates

\begin{tabular}{|c|c|c|c|c|c|c|c|c|c|}
\hline \multirow{2}{*}{$\begin{array}{c}\text { Slag Id } \\
\text { No. }\end{array}$} & \multicolumn{2}{|c|}{ Density } & \multicolumn{2}{|c|}{ Nordic Ball mill } & \multicolumn{3}{|c|}{ Los Angeles and Micro Deval } & \multicolumn{2}{|c|}{ Flakiness Index } \\
\hline & Fraction & $\mathrm{g} / \mathrm{cm}^{3}$ & Fraction & $\mathrm{A}_{\mathrm{N}}$ & Fraction & $\mathrm{M}_{\mathrm{DE}}$ & LA & Fraction & FI \\
\hline 1 & $8 / 11.2$ & 3.58 & $11.2 / 16$ & 12.6 & $10 / 14$ & 9 & 15 & $8 / 16$ & 3 \\
\hline 2 & $11.2 / 16$ & 3.40 & $11.2 / 16$ & 32.9 & $10 / 14$ & 19 & 31 & $4 / 16$ & 6 \\
\hline 3 & $8 / 11.2$ & 3.03 & $8 / 11.2$ & 9.1 & - & - & - & - & - \\
\hline 3 & $11.2 / 16$ & 3.03 & $11.2 / 16$ & 11.8 & $10 / 14$ & 8 & 19 & - & - \\
\hline 3 & $11.2 / 16$ & 3.02 & $11.2 / 16$ & 17.6 & $10 / 14$ & 10 & 28 & $4 / 31.5$ & 3.8 \\
\hline 4 & $11.2 / 16$ & 2.88 & $11.2 / 16$ & 14.6 & $10 / 14$ & 13 & 18 & - & 6 \\
\hline 4 & $8 / 11.2$ & 2.88 & $8 / 11.2$ & 13.3 & - & - & - & - & - \\
\hline 4 & $11.2 / 16$ & 2.54 & $11.2 / 16$ & 22.1 & - & - & - & - & - \\
\hline 5 & $8 / 11.2$ & 2.71 & $8 / 11.2$ & 12.1 & $8 / 11.2$ & 11 & 20 & - & - \\
\hline 6 & $8 / 11.2$ & 3.81 & $8 / 11.2$ & 8.6 & - & - & - & - & - \\
\hline 7 & $8 / 11.2$ & 3.23 & $8 / 11.2$ & 10.5 & - & - & - & - & - \\
\hline 7 & $10 / 12.5$ & 3.23 & $11.2 / 16$ & 10.0 & $10 / 14$ & 8 & 16 & $8 / 16$ & 6 \\
\hline 8 & $8 / 11.2$ & 3.54 & $8 / 11.2$ & 8.2 & - & - & - & - & - \\
\hline 8 & - & - & - & - & $10 / 14$ & 7 & 14 & $4 / 16$ & 5 \\
\hline 9 & $8 / 11.2$ & 3.18 & $8 / 11.2$ & 20.5 & $8 / 11.2$ & 14 & 26 & - & - \\
\hline 9 & $11.2 / 16$ & 3.45 & $11.2 / 16$ & 12.9 & $10 / 14$ & 9 & 17 & $8 / 11,11 / 16$ & $2 \& 1$ \\
\hline 9 & $8.0 / 10$ & 3.46 & $11.2 / 16$ & 12.9 & $10 / 14$ & 10 & 16 & $8 / 16$ & 3 \\
\hline 10 & $8 / 11.2$ & 3.56 & $8 / 11.2$ & 14.1 & - & - & - & - & - \\
\hline 10 & $8 / 11.2$ & 2.68 & $8 / 11.2$ & 29.4 & - & - & - & - & - \\
\hline 10 & $11.2 / 16$ & 2.85 & $11.2 / 16$ & 15.2 & - & - & - & - & - \\
\hline
\end{tabular}

Note: $-=$ data missing.

\subsection{Slag Asphalt Mix Performance}

\section{Prall Test}

Figure 2 presents the result of the Prall test. The Prall test values indicate that most of the slag asphalt mixes fulfill the wear resistance classes of Satisfactory (S) to Good (G) according to general guidance for Prall test (VG $=$ Very Good, G $=$ Good, $\mathrm{S}=$ Satisfactory, $\mathrm{LS}=$ Less satisfactory and $\mathrm{P}=$ Poor) [7]. The Prall test for slag no 2 was not conducted due to high crushing trend of the slag aggregates as observed in other aggregate tests.

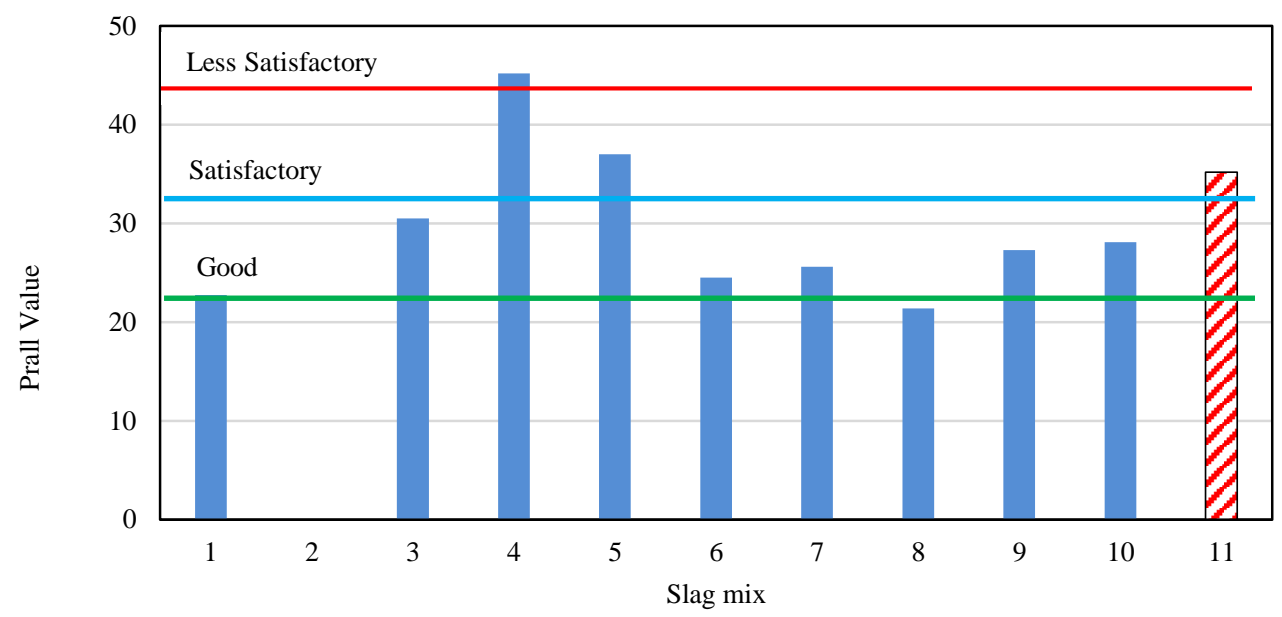

Figure 2: Prall test result (No 11 is the reference mix) 


\section{Dynamic Creep Test}

Figure 3 presents creep deformation of the ten slag asphalt mixes and the reference mix. As is shown in the figure, most of the slag asphalt mixes produced a better performance to permanent deformation compared to the reference mix. It is essential to note that the results or the ranking of the mixes might have been affected by the differences in the air void and binder content among the different slag mixes as indicated in Figure 1 and Table 1. More so, despite having a higher air void than the reference mix, the performance of most of the slag mixes exceeded or matched the performance of the reference mix. This might be attributed to the fact that slag asphalt mixes were made of stronger and angular slag aggregate particles having good adhesion and interlock properties, thus resulting in mixes with a higher shear resistance.

The creep deformation in Figure 3 can be divided into two phases, the primary and secondary. The primary or the initial part of the deformations is mainly due to volume change or packing of the mixes due to insufficient compaction during construction. The secondary phase of the permanent deformation is due to accumulation of micro damages and is related to the mix properties and its components such as physical and chemical properties of the slag and the adhesion between the slag and the binder $[9,10]$. The secondary phase is characterized by the rate of permanent deformation (the slope of the secondary part of the curve or creep rate). Note, differences in the rate of permanent deformation could be influenced by differences in air voids content as reported above. Mixes 7 and 8 show significantly better resistance to creep deformation than other mixes. An appropriate mix design of each slag type could further enhance the creep characteristic of the mixes.

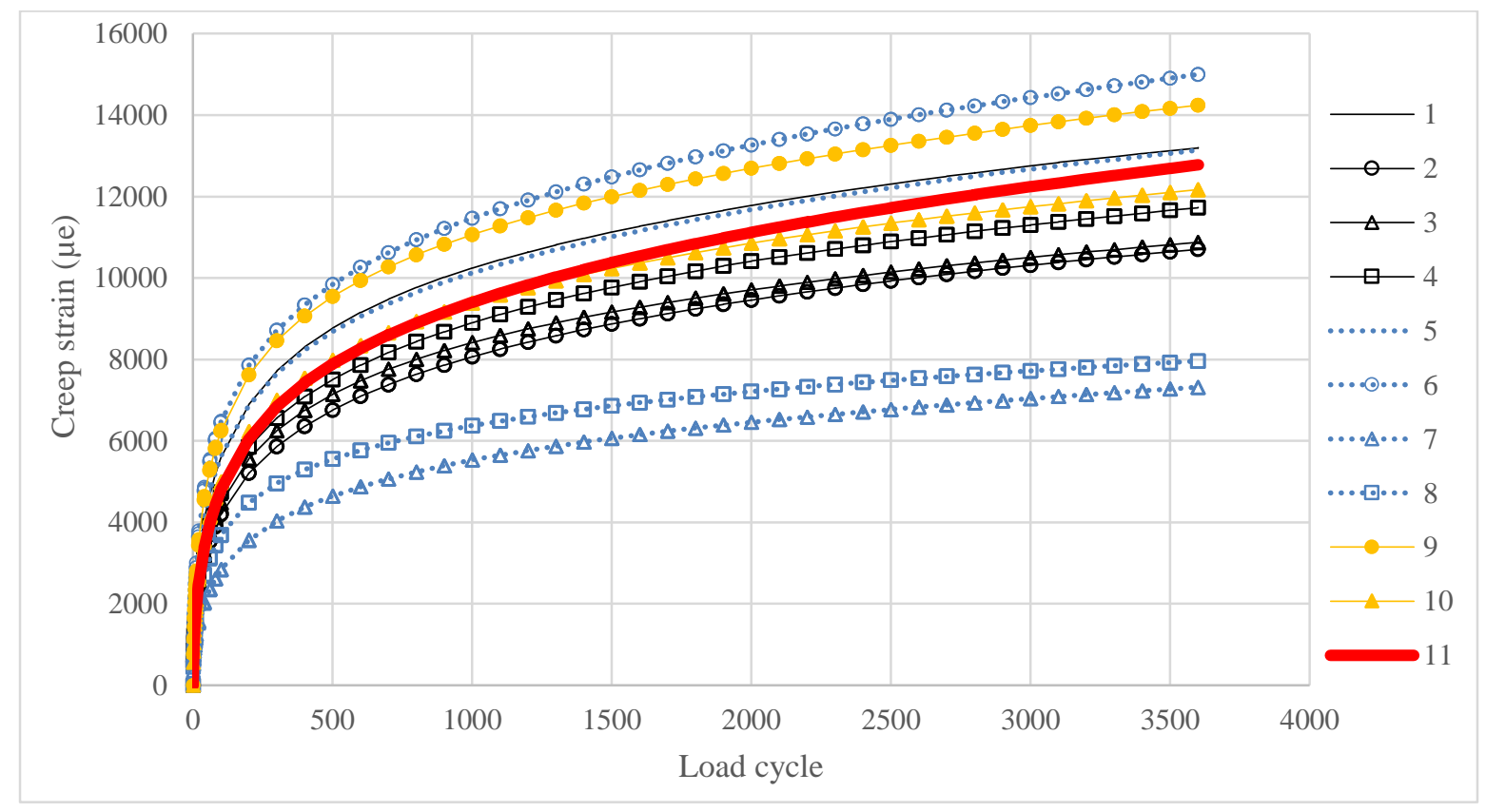

Figure 3: Dynamic creep strain of the slag asphalt mixes (No 11 is the reference mix).

Figure 4 shows the creep rate of the slag mixtures. Nine of slag mixes showed lower creep rate than the reference mix (shown in red) with conventional aggregate, indicating that the long term performance of the binder layer mixes might be enhanced by employing the slag aggregates.

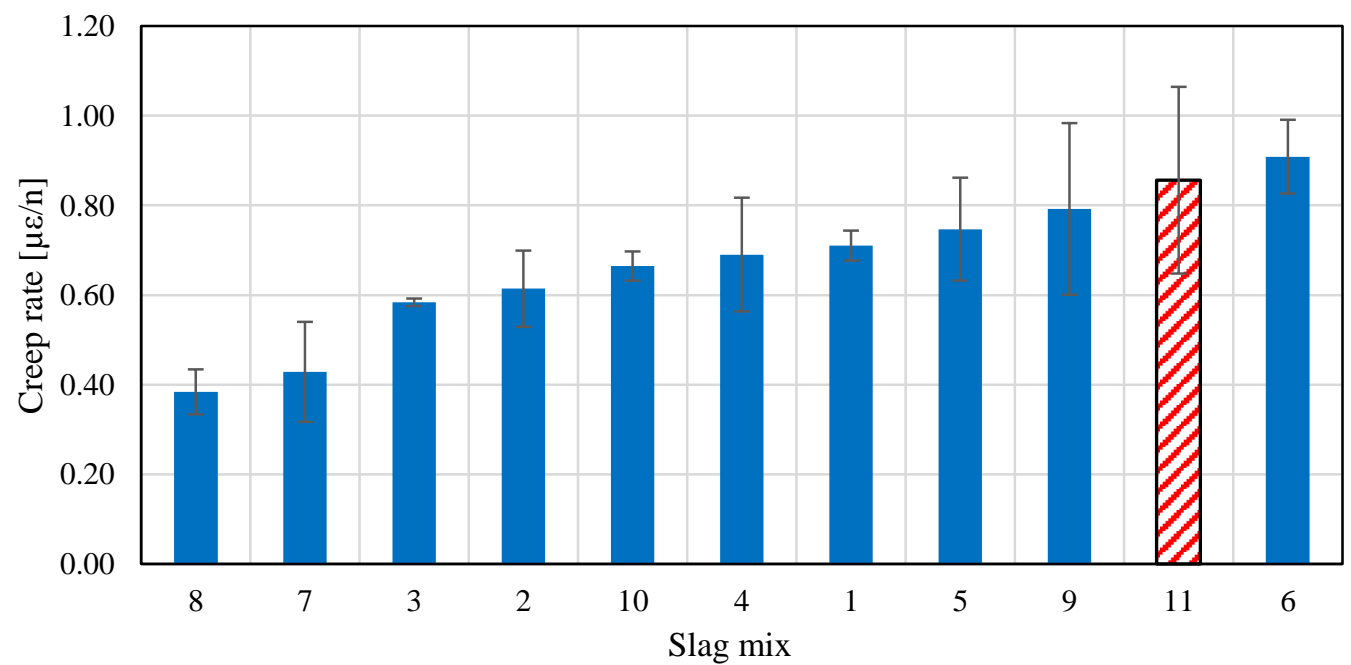


Figure 4: Creep rate of the slag asphalt mixes (No 11 is the reference mix)

Dynamic shear modulus test

The dynamic shear modulus test was carried out to evaluate the performance of the slag mixes under wider ranges of temperatures and loading frequencies. The tests were conducted at a temperature ranging from -10 to $50{ }^{\circ} \mathrm{C}$ and loading frequencies were varied from 0.01 to $25 \mathrm{~Hz}$. The results are presented in Figure 5 in the form of master curves for the dynamic shear modulus and phase angle of the 10 slag asphalt mixes and the reference mix.

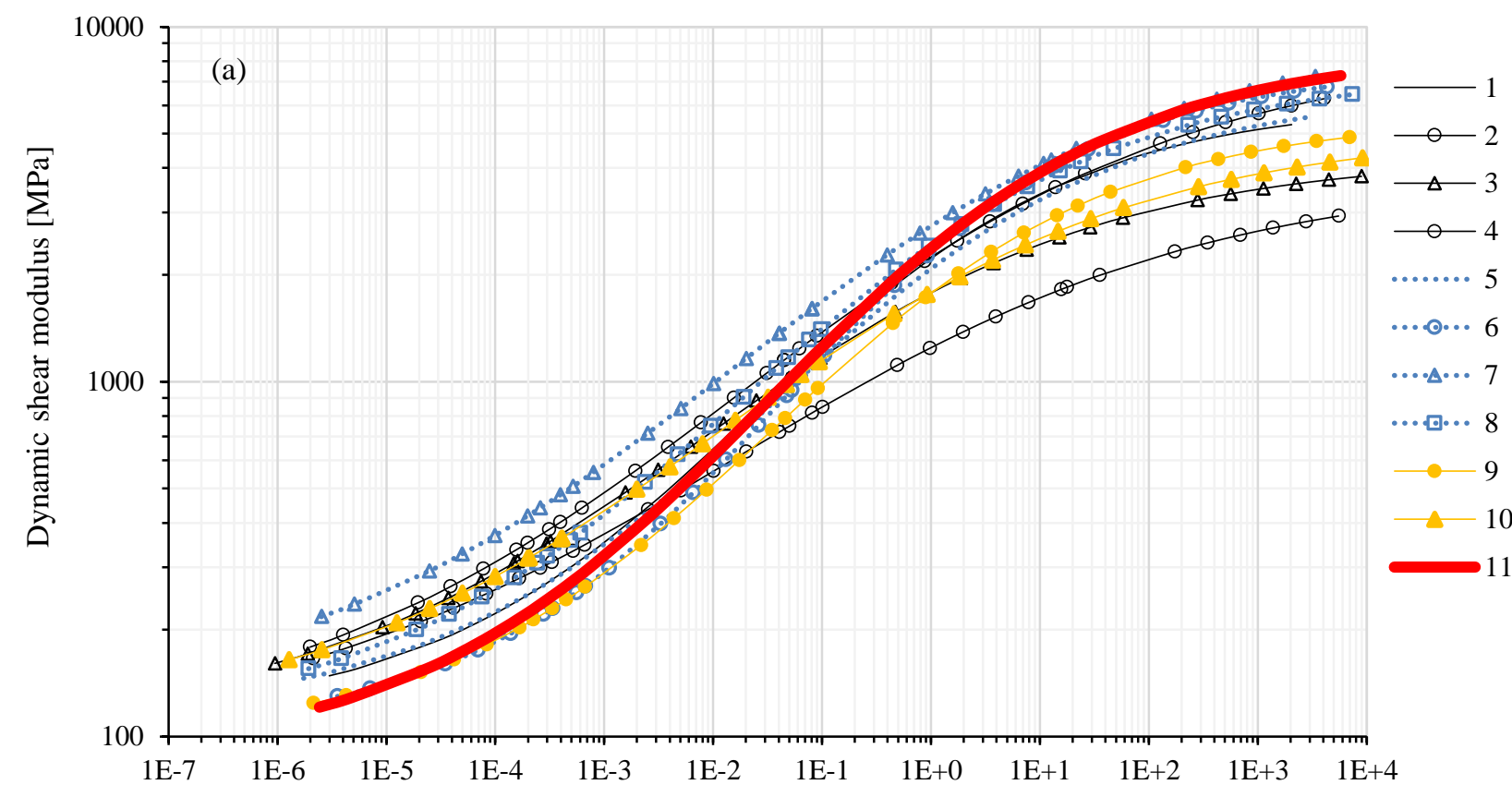

Reduced frequency $[\mathrm{Hz}]$

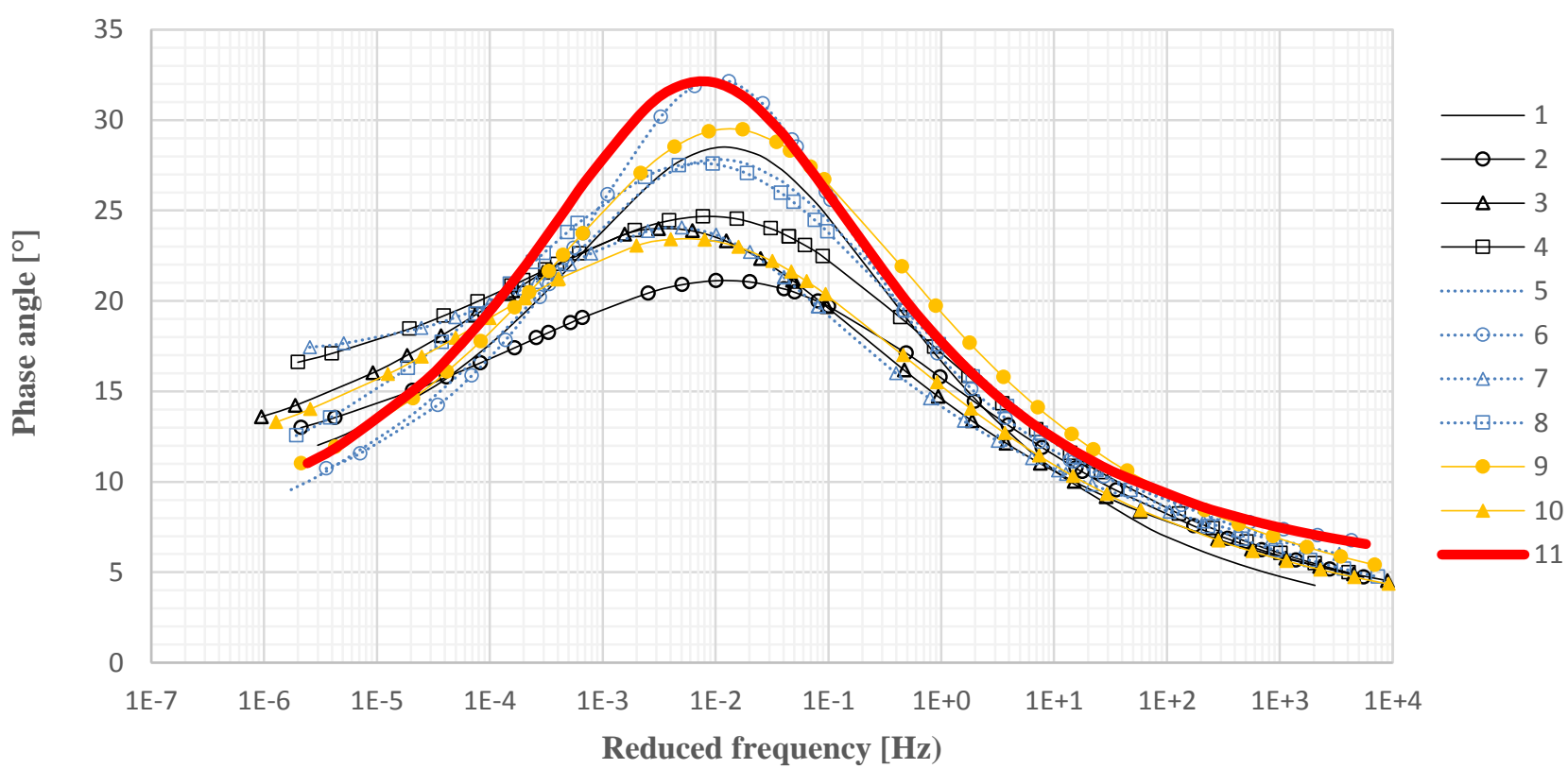

Figure 5: Master curves for (a) shear modulus and (b) phase angle of the slag mixes. (No 11 is the reference mix).

It can be observed that the master curves for the slag mixes, Figure 5a, are flatter than the one for the reference mix, which indicates that the slag mixes perform well under wider loading frequency (traffic speed) and temperature spectra. Furthermore, it is known that in the high temperature and low frequency region, there is a high risk of rutting of conventional asphalt mixes. All the slag mixes, however, produced a higher modules at high temperatures and/or low frequencies (lower left side of the figure) than the conventional mixture, in other words, the slag mixes have better 
resistance to rutting. Moreover, in the low temperature and high frequency region (top right side of the figure), the slag mixes produced lower modules/stiffness which means more flexible and thus better resistance to cracking (can withstand considerable deformation before rupture).

Therefore, by using slag mixes, it might be possible to reduce both the risk of rutting at high temperatures and the risk of cracking at low temperatures. These are the properties of asphalt mixes that pavement engineers wish to attain during the mix design processes by using different types of binder modifiers. Most binder modifiers, however, improve the properties of the asphalt mixture only on one side of the temperature or frequency spectrum (i.e. low temperature/high frequency or high temperature/low frequency regions). The master curves for the phase angle of the slag mixes, Figure 5b, also lead to similar conclusions. Most of the slag mixes are characterized by lower peak values compared to the reference mix. Asphalt mixtures exhibit unique characteristics of both viscous and elastic properties, and hence are categorized as viscoelastic materials. For a purely elastic material the phase angle is $0^{\circ}$; and for a purely viscous material, the phase angle is $90^{\circ}$ [8]. Therefore, lower peak values of the phase angle indicates that the material is more elastic, thus less susceptible to both rutting and cracking. Noteworthy, the reference mix No 11 and the mix No 6 show the highest phase angle values, the lowest shear modulus at the left side of the Figure 5a and the highest creep rate (Figure 4) demonstrating similar conclusions from the tests. The mixes No 11 and 6 have almost the lowest air voids contents.

For the purpose of validation, the normalized shear modulus and creep modulus are presented in Figure 6. The shear modulus was obtained from the master curves in Figure $5 \mathrm{a}$ at a temperature of $40{ }^{\circ} \mathrm{C}$ and a loading frequency of $0.5 \mathrm{~Hz}$ that corresponds to the temperature and loading frequency of the dynamic creep test. The normalization was done by dividing the dynamic shear modulus and creep modulus of the slag mixes by the corresponding values of the reference mix. The two independent tests procedures show very similar ranking of the slag mixtures.

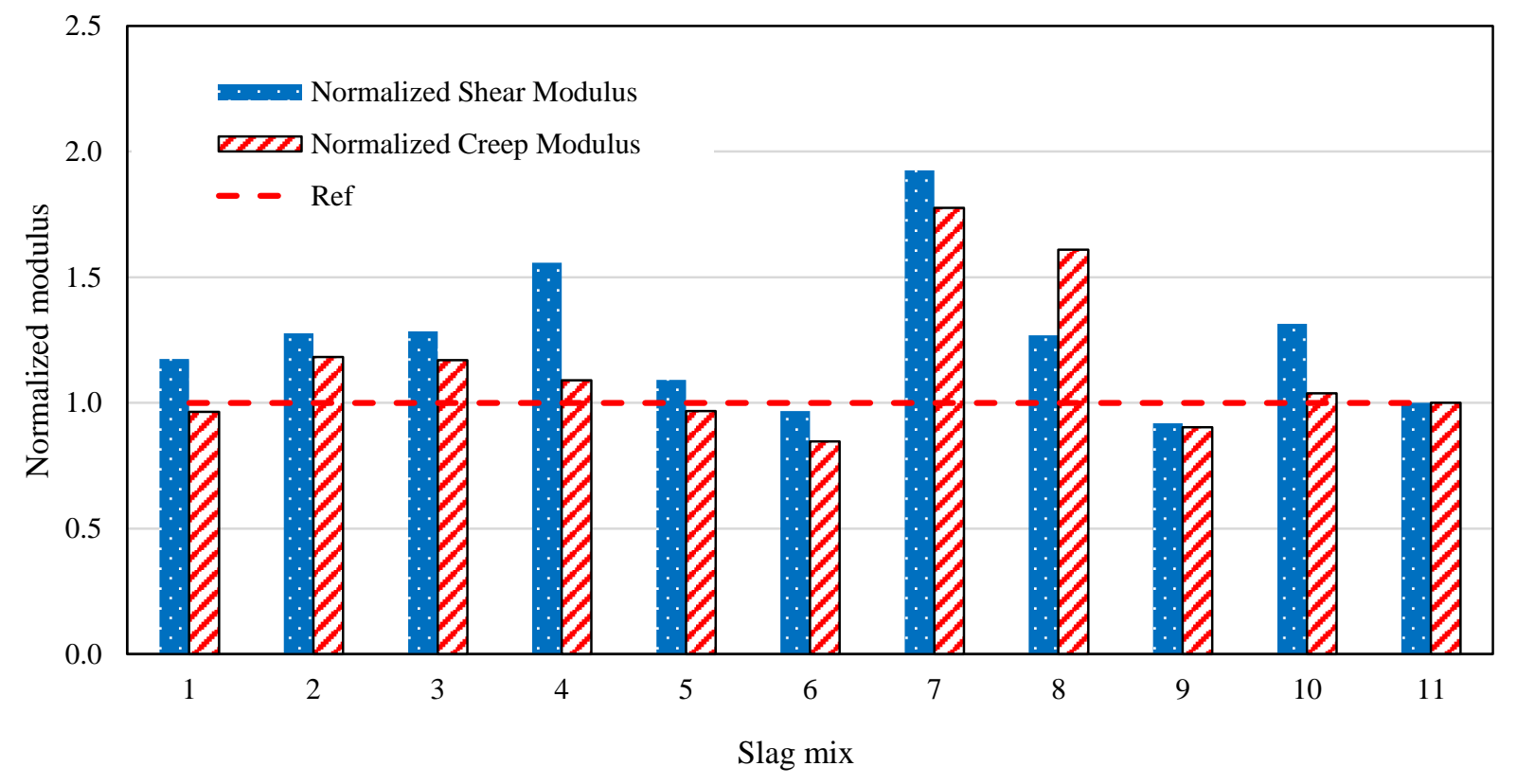

Figure 6: Normalized shear modulus and creep modulus values of the slag mixes (Slag mix 11 is the reference mix).

\section{CONCLUSIONS AND RECOMMENDATIONS}

The paper reports the performance evaluation of slag aggregates and slag aggregate asphalt mixes obtained from 10 different Swedish slag suppliers/steel producers. The evaluation was carried out based on laboratory tests. Tests conducted on the slag aggregates included abrasion and flakiness tests whereas tests conducted on the slag asphalt mixture were the Prall test for wear resistance, dynamic creep and dynamic shear modulus tests which are traditionally used as indicators of the resistance to wearing and rutting of asphalt mixtures. The following conclusions can be drawn from the study:

- The slag aggregate performance tests showed that the wear resistance of most of the slag aggregates exceeded or matched the requirements for road aggregates.

- The dynamic creep test demonstrated a better short term and long term performance of the slag asphalt binder mixes than the reference mix with conventional natural aggregate.

- The dynamic shear modulus tests indicated that the slag asphalt binder mix performed better than the conventional for a wider range of temperatures and frequencies and therefore might reduce the risk of both rutting and fatigue cracking. 


\section{Acknowledgements}

We wish to thank Vinnova for the financial support of the research performed.

We also wish to thank all Swedish slag producers for supplying slag samples for the tests and all members of the project group for very fruitful discussions.

\section{REFERENCES}

[1]. Jacobson T., Stålslagg i asfaltbeläggning - Kunskapsöversikt. VTI Notat 5-2008 (In Swedish), Swedish National Road and Transport Research Institute, 2008.

[2]. Jacobson T. and Göransson, N.G., Stålslagg i asfaltbeläggning. Fältförsök 2005 - 2012. VTI Notat 19-2013 (In Swedish), Swedish National Road and Transport Research Institute, 2013.

[3]. The European Slag Association, Chemical Safety Report, Ferrous Slag from the REACH Ferrous Slags Consortium, 2012.

[4]. NCHRP Report 465. Simple Performance Test for Superpave Mix Design. Transportation Research Board, National Research Council, Washington, D.C, 2002.

[5]. Produktstandarden. Ballast för asfaltmassor och tankbeläggningar för vägar, flygfält och andra trafikerade ytor (In Swedish). SS-EN 13043: 2003.

[6]. Jacobson T. and Viman L., Modifiering av Prallmetoden och nordisk ringanalys. VTI Notat 58-1998 (In Swedish), Swedish National Road and Transport Research Institute, 1998.

[7]. Viman L., Slaggasfalt, delrapport A, Ballastegenskaper och slitageegenskaper enligt Prall (In Swedish), VTI notat 10-2015, Swedish National Road and Transport Research Institute, 2015.

[8]. Said. S., Hakim H. and Eriksson O., Rheological characterization of asphalt concrete using a shear box. ASTM Journal of Testing and Evaluation, Vol. 41, No. 4, 2013, pp. 602-610.

[9]. Viman L. and Said S., Slaggasfalt, delrapport B: Stabilitet och skjuvegenskaper hos slaggasfalt (In Swedish), VTI notat 19-2015, Swedish National Road and Transport Research Institute, 2015.

[10]. Said S., Hakim H., Oscarsson E. and Hjort M., Prediction of flow rutting in asphalt concrete layers, International Journal of Pavement Engineering, Vol. 12, No. 6, pp. 519-532. 